\section{Agricultura em zonas ripárias do sul do Brasil: conflitos de uso da terra e impactos nos recursos hídricos}

Recebido:

23/09/10

Aprovado:

12/09/11

1. Professor Associado da Universidade Federal de Santa Catarina.

E-mail:

Imartini@cca.ufsc. br

2. Instituto Estadual de Meio Ambiente e Recursos Hídricos do Estado do Espírito Santo.

E-mail: etrentini@yahoo. Luiz Carlos Pittol Martini ${ }^{1}$ e Élen Cristin Trentini ${ }^{2}$

Resumo: 0 trabalho apresenta e discute a questão da proteção de zonas ripárias em áreas agrícolas do Sul do Brasil, em especial no Estado de Santa Catarina, em que predomina agricultura familiar praticada em pequenas propriedades. As exigências legais determinadas pelo Código Florestal brasileiro de 1965 são apresentadas frente às limitações para atendimento da lei impostas por fatores culturais, do meio físico e do tamanho das propriedades agrícolas. Para ilustração do problema, são confrontadas as duas correntes preponderantes no debate a respeito da utilização de áreas ripárias em Santa Catarina: aplicação dos dispositivos legais existentes versus flexibilização da lei para atender usos atuais em áreas de preservação permanente.

Palavras-chave: Zonas Ripárias, Matas Ciliares, Recursos Hídricos, Agricultura Familiar, Florestas.

\title{
Introdução
}

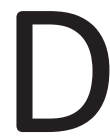

ados gerais de uso da água para o Brasil apontam que a agricultura é responsável por $62 \%$ das captações totais, percentual muito superior aos registrados pelos setores doméstico e industrial, que utilizam $20 \%$ e $18 \%$ do total, respectivamente (GLEICK, 2009). Embora possa surpreender, a participação da agricultura brasileira na partilha dos recursos hídricos é inferior à média mundial, situada em torno dos $70 \%$. A irrigação é a grande responsável por esses percentuais e responde por parte importante dos conflitos de uso da água em todo o mundo.

As consequências do uso das águas para irrigação são suficientemente claras para despertar interesse dos gestores públicos, dos cidadãos e organizações sociais. Por outro lado, nem sempre são considerados de forma adequada os impactos indiretos aos recursos hídricos decorrentes das atividades agrícolas, 
principalmente nas situações em que os danos são difusos, distribuídos espacialmente e aos quais dificilmente se pode apontar o causador. Dentre esses impactos, destacam-se a poluição agrícola não pontual, a erosão do solo, os impactos hidrológicos devido aos desmatamentos e a ocupação de terras marginais aos cursos de água. Esse último problema é o que será tratado neste texto.

Terras marginais aos cursos de água são denominadas zonas ripárias e, no Brasil, costuma-se chamá-las também de faixas ciliares ou vegetação ciliar. Como originalmente eram cobertas principalmente por vegetação arbórea, são mais conhecidas como matas ciliares ou, menos frequentemente, como matas de galerias. Ab'Saber (2001) as denominou simplesmente de florestas beiradeiras, enquanto que Rodrigues (2001) fez ampla discussão acerca das variantes dessas formações e da nomenclatura. Dada a importância dessa vegetação aos recursos hídricos, principalmente no que se refere à sua influência nas trocas bilaterais entre terras altas e os cursos de água, ela foi contemplada em lei no Código Florestal de 1965 (BRASIL, 1965), que especificou larguras mínimas de proteção para diferentes dimensões dos corpos hídricos envolvidos. A faixa de mata ciliar regulada pela lei recebe a denominação de Área de Preservação Permanente (APP), a indicar que seu uso é vetado para qualquer fim que não seja preservação ambiental.

No entanto, condicionantes históricos impuseram a ocupação das zonas ripárias com agricultura, principalmente cultivos anuais em áreas desmatadas. O uso das áreas marginais aos cursos d'água ocorreu por diversas razões, mas, para rios de pequeno porte, podem-se apontar como principais a pequena extensão das propriedades rurais (minifúndios) e as condições mais favoráveis das terras para agricultura nas margens, seja pelo relevo menos acidentado, pela qualidade do solo ou pela proximidade da água. Dessa forma, a tradição agrícola, em diversas regiões brasileiras e no sul do Brasil, em particular, é conflitante com o ordenamento jurídico que estabelece proteção da mata ciliar, situação evidenciada pelo grande número de casos em que a lei não é obedecida.

Assim, o objetivo deste trabalho é apresentar e discutir o problema de conflito entre uso agrícola das terras e proteção ambiental em zonas ripárias de rios de pequeno porte do sul do Brasil. Para emoldurar o problema, serão trazidos alguns condicionantes históricos, uma discussão sobre a agricultura familiar e o domínio dos terrenos situados na faixa ciliar. Na parte final, abordam-se aspectos ligados à conformidade das atividades agrícolas com respeito ao Código Florestal de 1965 (BRASIL, 1965) e a pressão política para sua mudança, exemplificando com as alterações trazidas pelo Código Estadual de Meio Ambiente de Santa Catarina (SANTA CATARINA, 2009). 


\section{Antecedentes}

No sul do Brasil, tal como no restante do país, a ocupação iniciou pelo litoral. No entanto, ao contrário de outras regiões com rios navegáveis que adentravam o continente, o avanço para o interior esbarrou nas escarpas da Serra do Mar e Serra Geral, com seus mais de 1000 metros de altitude média e que atingem ao redor de 1700 metros nos pontos mais elevados de Santa Catarina. Essas barreiras ainda são mais imponentes devido ao fato de se elevarem bruscamente, sem a presença de gradientes suaves a facilitar sua transposição. Incidentalmente, a ocupação das áreas de serras e vales profundamente entalhados foi relativamente tardia no transcurso da colonização lusitana, que inicialmente privilegiou a interiorização por navegação fluvial, marca característica do colonizador europeu e que determinou o nascimento de diversas povoações ao longo das margens de rios de grande e médio porte. Já nessa primeira fase de colonização, a ocupação se deu às custas de derrubada da mata ciliar, uma vez que os povoamentos foram firmados marginalmente aos cursos d'água, em terras elevadas apenas o suficiente para haver proteção contra as enchentes de maior frequência. Mas, como a densidade populacional e o avanço para o interior do continente eram incipientes, os impactos hidrológicos certamente foram insignificantes nos primeiros tempos. No entanto, diversas cidades atualmente exibem as marcas de sua fundação: presença de edificações, estradas e outras instalações urbanas nas margens dos rios, riachos e córregos e profundas alterações no regime hidrológico das bacias hidrográficas nas quais se inserem, a comprovar que há uma nítida linha histórica que liga a ausência ou degradação atual da mata ciliar e a forma como se deu a ocupação no passado.

Embora essencialmente similares, a evolução da ocupação agrícola das margens dos rios diferiu da urbana em extensão e intensidade. Enquanto a agricultura pôde se estender por grandes áreas ao longo dos rios, os núcleos urbanos foram limitados a áreas proporcionalmente menores das bacias, o que geralmente implicou em maior supressão da mata ciliar na zona rural do que na urbana. Além disso, a agricultura avançou sobre terrenos impróprios para formação de cidades, como é o caso das várzeas mal drenadas e cabeceiras íngremes de cursos d'água.

Em Santa Catarina, em especial, o relevo acidentado sempre representou um entrave à atividade agrícola. Para Peluso (1991), enquanto o fundo dos vales era desmatado para instalação de pastos e plantações, no alto das serras de onde desciam os ribeirões encachoeirados, as terras permaneciam virgens e não acendiam a cobiça dos colonos, pois sua aptidão para agricultura era inferior a das várzeas e as estradas de acesso, tendo que vencer as escarpas dos saltos dos rios, desencorajavam a aquisição de propriedades e o uso econômico dos terrenos mais elevados. Portanto, mesmo com baixa densidade populacional, 
a concentração humana nos vales determinou pressão exagerada sobre as áreas potencialmente agricultáveis, o que resultou em desmatamentos indiscriminados por meio de queimadas e formação de lavouras anuais e pastos.

É importante frisar que a eliminação da mata não visava, nos primeiros tempos, à exploração econômica da madeira, o que resultou em enormes desperdícios de capital natural. Na verdade, Dean (1996) destaca que os imigrantes europeus que colonizaram Santa Catarina, inicialmente, adotaram a agricultura de coivara praticada pelos indígenas, método de cultivo itinerante que consiste em derrubada e queima da mata para formação de roças e que proporciona boas produtividades nos primeiros ciclos de cultivo, devido à pronta liberação de nutrientes, mas que também determina forte lixiviação e erosão hídrica e, dessa forma, rápida perda de fertilidade dos solos. Tradicionalmente, no entanto, os indígenas usavam o sistema de pousio prolongado (cerca de 20 anos) nas terras agrícolas, método que promove recuperação da cobertura arbórea e da fertilidade do solo, ao menos parcialmente. Já para os primeiros colonos, que necessitavam produzir excedentes para comercialização, o pousio era de dois ou três anos apenas e, na maioria dos casos, substituíam-se cultivos anuais por pastos, forma menos eficiente ou mesmo ineficaz de recuperação da fertilidade do solo.

Portanto, com a redução das produtividades nas áreas inicialmente cultivadas pelos colonos e também devido ao crescimento das famílias nas colônias mais antigas e consequentes fluxos migratórios, o processo de ocupação se deu indiscriminadamente em direção às cabeceiras dos cursos d'água e em encostas mais íngremes, locais com declividades mais acentuadas e solos mais suscetíveis à erosão hídrica e perda de nutrientes. Enfim, em determinado estágio, cada vez mais novas áreas eram gradativamente incorporadas ao processo produtivo devido à cada vez mais rápida perda de produtividade dos terrenos inadequados a cultivos anuais. Em alguns locais, esse processo ocorreu até a eliminação completa das florestas originais. Paradoxalmente, em algumas regiões, a exploração econômica da madeira desacelerou o processo de desmatamento generalizado, pois substituiu a agricultura como fonte de renda principal ou a complementou. Nesse momento, a floresta deixou de ser apenas um estorvo à expansão agrícola e passou a ter valor intrínseco aos olhos dos colonos. De certa forma, uma incipiente derrubada seletiva foi promovida, pois as árvores passaram a ser consideradas como reserva de renda. Ainda que sem uma visão do real valor da floresta, esse comportamento utilitarista preservou do fogo muitas áreas que, ainda hoje, se mantêm, embora com uma fração mínima do original.

Em síntese, a ocupação do interior do território sul brasileiro se deu às custas da derrubada das florestas nativas, que foi largamente incentivada pelos governos até recentemente (pelo menos até os anos 1970). O desmatamento realizado ao longo de mais de um século, desde a instalação das primeiras colônias, 
formadas principalmente por imigrantes italianos e alemães, reduziu a cobertura florestal do estado de Santa Catarina para cerca de $21 \%$ da área original. Em 1500 , o Estado possuía $81,5 \%$ de seu território ocupado com florestas do bioma Mata Atlântica, enquanto que, em 1995, apenas cerca de 17\% da área total estadual estava coberta com florestas (CAPOBIANCO, 2001). O desmatamento inicialmente foi realizado como desbravamento, ou seja, a mata era eliminada pelo fogo para dar lugar às lavouras e pastos. $O$ uso da madeira era restrito às comunidades e era pouco aproveitada como fonte de renda. Posteriormente, em época histórica mais recente, a exploração florestal abateu grande parte das árvores capazes de fornecer madeira nobre: o ciclo da madeira, o qual pode ser dado como encerrado, encarregou-se de eliminar as florestas primárias em áreas inaptas à agricultura.

Assim, com relação às matas ciliares ocorreram duas ações principais em momentos históricos diferentes. No início da colonização, as queimadas generalizadas nos vales e encostas mais suaves suprimiram a vegetação arbórea ao longo de cursos d'água, uma vez que os solos às suas margens eram profundos, mais férteis e adequados às lavouras de subsistência e comerciais disponíveis. Nesse período, áreas às margens de rios encaixados e em terrenos íngremes foram mantidas intocadas. Posteriormente, com o crescimento da população, fluxos migratórios e exploração de madeira, grande parte dessas áreas inicialmente descartadas foi paulatinamente incorporada à agricultura, com consequente eliminação da vegetação, seja ela marginal aos rios ou não.

Agricultura familiar e uso de terras em áreas de preservação permanente

Para Wanderley (1996), agricultura familiar é entendida como aquela em que a família, ao mesmo tempo em que é proprietária dos meios de produção, assume o trabalho no estabelecimento produtivo. Para incluir outras modalidades de vínculo à terra, como posse, por exemplo, autores como Denardi (2001) preferem apontar que, na agricultura familiar, os empreendimentos agrícolas são administrados pela própria família e, neles, os membros familiares trabalham diretamente, com ou sem auxílio de terceiros. Em síntese, a gestão é familiar e o trabalho é predominantemente familiar.

Em Santa Catarina, como de resto em grande parte do Brasil, a agricultura familiar constitui a principal forma de organização rural. De acordo com dados do Levantamento Agropecuário de Santa Catarina 2002-2003 (CEPA, 2008), de um total de 187.061 estabelecimentos agropecuários em atividade, 173.918 são enquadrados como pequenas propriedades. Uma vez que pequenas propriedades rurais são essencialmente empreendimentos familiares, pode-se 
considerar que, em cerca de $93 \%$ dos estabelecimentos agropecuários catarinenses, pratica-se agricultura familiar e que esta é única modalidade presente em diversos municípios.

É importante destacar que, na agricultura familiar típica, as atividades agrícolas confundem-se com as atividades domésticas, no sentido de que as lavouras ou criações são extensões da casa, em geral havendo uma estreita relação entre produção e consumo. Tal relação implica em destinar toda ou parte da produção ao consumo da família, fato que demonstra ser a atividade herdeira de uma forte tradição que reproduz costumes ancestrais e estreita laços de identidade entre os integrantes da família e comunidade. Em tal contexto, as terras marginais aos cursos d'água, que deveriam estar ocupadas pela mata ciliar, são uma extensão da área de entorno das residências, quando não as próprias residências e construções contíguas ocuparem as margens ou estarem locadas sobre o leito do rio. Como ilustração, embora atualmente seja incomum, há poucos anos podia-se, facilmente, encontrar, no interior do sul do Brasil, instalações para criação de animais domésticos que se estendiam sobre o leito de cursos d’água.

Além de a agricultura familiar ter uma evidente relação com as atividades domésticas e, muitas vezes, não haver nítida separação entre as duas - e isso implicar em áreas de preservação incorporadas ao "quintal" da casa - outros fatores concorrem para o uso agrícola das terras marginais aos cursos d'água. Entre eles, pode-se destacar os seguintes:

- Direito ribeirinho não formal: no meio rural, em geral não há dissociação entre posse da terra e posse de componentes ambientais. Assim, para o agricultor não existe irregularidade no uso da faixa de proteção ciliar, pois ela ocupa terrenos incorporados à área total da propriedade. Por extensão, o uso das águas ou matas se dá nesse mesmo sentido: se estiverem na propriedade, dela fazem parte e, ao menos informalmente, podem ser desfrutadas de acordo com os interesses do proprietário;

- Fator cultural: na formação de comunidades agrícolas no sul do Brasil, a eliminação da mata implicava em posse, de fato, da terra. Presença de "mato" poderia indicar áreas incultas e revelavam "desleixo" ou "preguiça" de seu proprietário. De certa forma, muitos agricultores, ainda hoje, consideram que os terrenos com mata sem reserva de valor (madeira ou lenha) devem ser transformados em lavouras ou pastagens, independente se tal transformação acrescentar ou não renda significativa ao proprietário. 
- Tamanho da propriedade: em algumas regiões, a ampliação da renda agrícola apenas pode-se dar pela ampliação da área de cultivos ou pastagem. Ocorre, então, uma forte pressão sobre os terrenos situados em áreas inaptas ou de preservação permanente. Da mesma forma, a progressiva degradação das áreas mais favoráveis induz à ocupação de outros terrenos disponíveis na propriedade, invariavelmente situados em locais como margens de cursos d'água ou encostas íngremes. Evidentemente, existe uma clara relação inversa entre tamanho da propriedade e pressão sobre áreas de preservação permanente.

- Aspectos fisiográficos da bacia: independente dos itens anteriores, há que se considerar o fato de que, em muitos locais, as áreas mais adequadas aos cultivos e pastagens são justamente aquelas situadas nas margens dos cursos d'água, que podem apresentar solos com relevo e propriedades físico-químicas favoráveis à agricultura. Em algumas situações emblemáticas, o uso agrícola de certas propriedades rurais está condicionado à ocupação das faixas ciliares. $O$ inverso ocorre em outras situações: cursos d'água encaixados apresentam áreas marginais íngremes, que são inaptas às atividades de cultivo ou criação e, dessa forma, são mantidas na sua condição natural. É importante salientar que a preservação, nesses casos, é imposta por restrições do meio físico e não está associada a fatores de ordem cultural, legal ou educacional.

Note-se, portanto, que mesmo a agricultura familiar praticada em pequena escala pode conflitar seriamente com a proteção ambiental. Se existe, de um lado, a sempre presente necessidade de produção agrícola e os impactos ambientais a ela associados, de outro crescem as demandas de diversos setores por bens e funções ambientais, com destaque para águas destinadas ao abastecimento de centros urbanos. Em decorrência, adquirem força apelos por legislação ambiental mais restritiva ou pela aplicação rigorosa dos dispositivos legais já existentes e que nem sempre são acionados pelos agentes públicos. Para ilustrar a dimensão do problema, a seguir serão confrontadas as duas correntes preponderantes no debate a respeito da utilização de áreas ripárias em Santa Catarina: aplicação dos dispositivos legais existentes, mesmo que de forma parcial ou gradativa, versus flexibilização da lei para atender usos atuais em áreas de preservação permanente.

\section{Aplicação do Código Florestal}


Na região sul do Brasil, os dispositivos do Código Florestal com maior repercussão para o uso das terras em pequenas propriedades sob agricultura familiar dizem respeito às Áreas de Preservação Permanente (APPs) e reserva legal, principalmente aqueles dispositivos discriminados no Artigo $2^{\circ}$ da Lei $n^{\circ} 4.771$, que institui o Código em 1965 (BRASIL, 1965). Nesse artigo, por exemplo, verifica-se que as florestas e demais formas de vegetação natural situadas

(...) ao longo dos rios ou de qualquer curso d'água desde seu nível mais alto em faixa marginal cuja largura mínima será: 1- de 30 (trinta) metros para cursos d'água de menos de 10 (dez) metros de largura; 2- de 50 (cinqüenta) metros para os cursos d'água que tenham de 10 (dez) a 50 (cinqüenta) metros de largura.

Como consequência da lei, mesmo que a maior parte dos cursos d'água que cortem pequenas propriedades possuam largura inferior a 10 metros, ainda assim deverá ser preservada, pelo menos, uma faixa contínua de 30 metros ao longo de cada margem, o que implica em apreciável redução da área aproveitável para cultivos ou pastagens. Pelas razões discutidas no item anterior - direito ribeirinho não formal, fator cultural, tamanho da propriedade e características fisiográficas das bacias hidrográficas -, essa redução potencial da área economicamente útil do imóvel rural nunca foi assimilada pelos agricultores e, na prática, o resultado é a desconsideração parcial ou total das normas estabelecidas no Código Florestal quanto às APPs, fato notório a ponto de ser desnecessária sua comprovação factual.

Dado o baixo grau de conformidade à lei e muitas vezes sob pressão de outros segmentos sociais, algumas vezes os órgãos ambientais estaduais ou federais fazem uso de suas atribuições para autuar agricultores e exigir o cumprimento da norma jurídica, no que diz respeito às APPs e também às reservas legais. No entanto, apesar dos mais de quarenta anos decorridos desde a publicação do Código Florestal, as ações promovidas pelos agentes públicos têm sido ineficazes na contenção do avanço agrícola ou na recuperação de terras indevidamente ocupadas com atividades agropecuárias. A aplicação de muitos dispositivos do Código Florestal compartilha das mesmas dificuldades instrumentais enfrentadas na aplicação de tantos outros regulamentos no Brasil, como fraca adesão da população, ausência de vontade política dos gestores públicos, território extenso aliado a número insignificante de fiscais e policiais, tradição de arranjos políticos para negociação da norma, pressão econômica de grupos hegemônicos e sistema judiciário desaparelhado.

Apesar das dificuldades instrumentais enumeradas, a questão central a emperrar a aplicação do Código Florestal está inserida logo no Caput do Artigo 1ㅇ da Lei no 4.771, no qual se lê que 
As florestas existentes no território nacional e as demais formas de vegetação, reconhecidas de utilidade às terras que revestem, são bens de interesse comum a todos os habitantes do País, exercendo-se os direitos de propriedade, com as limitações que a legislação em geral e especialmente esta Lei estabelecem.

O entrave está em bens de interesse comum, inscrito no campo dos direitos difusos, difíceis de delimitar em virtude de os titulares serem indeterminados. Para Trentini (2004), ao contrário dos direitos individuais, considerados como uma garantia do indivíduo diante do poder do Estado, e dos direitos sociais, que consistem em prestações que o Estado deve ao indivíduo, o direito difuso consiste num direito-dever, na medida em que a pessoa, ao mesmo tempo em que é titular do direito, tem também a obrigação de defendê-lo e preservá-lo. Deve-se apontar, portanto, as dificuldades impostas ao agricultor no tocante à compreensão do alcance da legislação: ao mesmo tempo em que ele, como qualquer cidadão, é detentor do direito da faixa ciliar enquanto bem de interesse comum, a ele é destinado à guarda desse bem e função ambiental. Ou seja, tem a posse de fato do bem, não possui direito a uso, mas lhe cabem as tarefas de zelar pela sua integridade. Ao fim e ao cabo, é um depositário do bem ambiental.

Uma experiência de aplicação do Código Florestal em Santa Catarina foi apresentada por Trentini (2004). Com base em denúncias e problemas no abastecimento público de água em alguns municípios, o Ministério Público do Estado de Santa Catarina constatou que grande parte das instalações físicas para criação de suínos e áreas de lavouras, na região catarinense do Alto Uruguai, encontrava-se em desconformidade com a legislação ambiental vigente, pois estava locada em áreas de preservação permanente. Isso conferia aos agricultores a situação de ilegalidade perante o Código Florestal e também diante da Lei 9.605/98 (BRASIL, 1998), denominada Lei de Crimes Ambientais, que, em seu artigo 38, atribui pena de 1 a 3 anos de prisão, multa, ou ambos, para quem "destruir, danificar ou cortar árvores da floresta considerada de preservação permanente sem a permissão da autoridade competente".

Diante desse quadro, em Embrapa (2003) pode-se verificar que restavam duas alternativas ao Ministério Público:

(...) a primeira, a aplicação da legislação ambiental e sanitária vigente ao pé da letra, resolvendo em parte o problema ambiental, mas por outro lado provocando conseqüências sociais e econômicas desastrosas para a região, e a segunda, buscar a solução do problema envolvendo todos os atores da cadeia produtiva, estabelecendo a responsabilidade de cada um, dentro dos prazos, condições e critérios estabelecidos em comum acordo. 
Com base na segunda alternativa, o Ministério Público do Estado de Santa Catarina, através da Coordenadoria do Centro de Apoio Operacional do Meio Ambiente, elaborou um Termo de Compromisso de Ajustamento de Conduta (TAC) aplicável aos produtores rurais da região catarinense do Alto Uruguai, em desconformidade com alguns dispositivos legais de proteção ambiental, principalmente no tocante à ocupação de áreas ripárias e ao lançamento de dejetos nos cursos de água. Para elaboração do TAC, o Ministério Público envolveu diversas instituições da região, como Embrapa, Consórcio Intermunicipal de Gestão Ambiental Participativa do Alto Uruguai Catarinense (Consórcio Lambari, constituído por 16 municípios), administrações municipais, câmaras de vereadores e organizações da sociedade civil, como associações comunitárias, clubes de serviços, cooperativas, etc.

Logo após a formalização dessa parceria interinstitucional, realizou-se um diagnóstico ambiental na área de abrangência do TAC, coordenado pela Embrapa, para caracterizar a situação de uma amostra de propriedades rurais frente à legislação ambiental. Em síntese, o diagnóstico (EMBRAPA, 2003) apontou a suinocultura como atividade predominante e com alto potencial de ocasionar problemas ambientais, pois, nos municípios abrangidos pelo estudo, 3.821 propriedades estavam envolvidas diretamente com essa atividade. Com relação à utilização de áreas de preservação permanente e sua situação frente à legislação, constatou-se que, em dois terços dessas propriedades, não havia cumprimento das distâncias mínimas entre a pocilga e elementos como rios, nascentes, estradas, divisas e residências. O diagnóstico apontou que, se fossem exigidas todas as normas referentes às APPs, grande parte das pequenas unidades de produção familiar não obteriam licenciamento pelo órgão ambiental.

Ao formular o TAC, o Ministério Público de Santa Catarina levou em conta o grau de descumprimento do Código Florestal observado na região do Consórcio Lambari, principalmente nos dispositivos referentes à vegetação ciliar, e estabeleceu um processo gradual de recomposição das áreas em desconformidade com a legislação. Dessa forma, o TAC determinava que apenas parte da faixa ciliar (10 metros, em geral) devesse ser isolada por cercas, em um tempo de até 24 meses, devendo a fração restante ser utilizada por sistemas de agroflorestas ou cultivos de espécies nativas em um prazo de até 60 meses.

Apesar da exigência de recomposição parcial e gradual da faixa ciliar, as metas do TAC foram atendidas apenas parcialmente na época de sua implantação e não existem avaliações recentes de seus resultados. Entraves quanto a aspectos físiográficos das propriedades rurais e, principalmente, a quem caberia os custos para implantação das obras para cercar a área efetiva a ser mantida sem uso limitaram a efetividade das medidas propostas. 
Mas o TAC, aplicado aos produtores rurais da região catarinense do Alto Uruguai, ocasionou muitas reações de agricultores e seus representantes políticos, que entendem as medidas do Código Florestal como restrições severas à produção agrícola. Infundadas ou não, tais reações resultaram em pressões para alterações na legislação que rege a matéria.

\section{A mudança do Código Florestal}

São comuns os argumentos que invocam a mudança da norma em face da baixa adesão da população. As mais de quatro décadas decorridas desde a publicação do Código Florestal, em 1965, e o baixo índice de conformidade a ele por parte dos agentes econômicos conduziram, ao longo dos anos, a sistemáticas pressões políticas para tornar mais flexível alguns dispositivos ou mesmo para suprimilos. Invariavelmente, o clamor para mudança na legislação é acompanhado de apelos contra os problemas socioeconômicos que advêm da aplicação à letra de dispositivos que constam do Código Florestal.

No momento, os argumentos favoráveis à mudança do Código Florestal estão em vantagem com relação às teses contrárias. Em Santa Catarina, o movimento pró-mudança antecedeu ao debate nacional, atualmente em curso, e levou à criação de diversas normas que abrandam a questão das faixas ciliares. Tais itens fazem parte do Código Estadual do Meio Ambiente (SANTA CATARINA, 2009) e ferem o Código Florestal de 1965, que, por se tratar de lei federal, tem precedência sobre uma lei estadual.

Não cabe abordar aqui aspectos da constitucionalidade ou não de dispositivos do Código Estadual do Meio Ambiente de Santa Catarina, questão mais apropriada a uma discussão tipicamente jurídica. Porém, não se pode deixar de apreciar algumas questões técnicas subentendidas nesse Código e suas implicações imediatas.

A principal questão técnica diz respeito aos conceitos de curso de água e nascente adotados no Código Estadual do Meio Ambiente. Nos itens XXII e XL do Artigo 28, claramente se pode identificar a preocupação do legislador em considerar um regime perene de vazão como atributo para definir um curso de água ou nascente, decisão que exclui aqueles com regime efêmero ou intermitente, isto é, os que apresentam disponibilidade hídrica episódica ou sazonal, respectivamente. A consequência imediata da aplicação do critério perenidade para definir um curso de água ou nascente é desobrigar a preservação ou recuperação da vegetação ciliar em diversos rios de pequena ordem (aqueles situados nas cabeceiras de drenagem) ou em nascentes que secam em alguma época do ano. Note-se que o Código Florestal de 1965 e a legislação complementar que se seguiu não fazem 
menção ao regime hidrológico de um corpo hídrico para seu enquadramento legal, restringindo-se a tratar da largura do rio como elemento objetivo de medida.

Considerando aspectos geomorfológicos e hidrológicos, não é concebível considerar como nascentes ou cursos de água apenas os que apresentam regime perene, pois mesmo vazões intermitentes ou efêmeras são capazes de criar ecossistemas diferenciados de seu entorno, moldar o terreno e formar leitos definidos de canais naturais. Em termos práticos, cursos de água efêmeros e intermitentes são até mais vulneráveis que os perenes, uma vez que em geral se situam em terrenos com maior declividade e as limitações hídricas periódicas podem determinar menor resiliência.

Embora os conceitos adotados para curso de água e nascente serem os que maior impactos poderiam causar à fração de uma propriedade rural ocupada com APPs, a questão técnica acerca do Código Estadual do Meio Ambiente de Santa Catarina que ocasionou maior debate durante a fase de tramitação legislativa e no período após a sanção do executivo foi a largura da faixa de mata ciliar a ser preservada. Sob a égide do Código Florestal, ao menos 30 metros ao longo de cada margem de um curso de água deveriam ser protegidos. No Código catarinense, entretanto, em seu Artigo 114, lê-se que a largura mínima varia desde 5 metros, para cursos de água com larguras inferiores a 5 metros e em propriedades rurais até 50 hectares, até 10 metros, para cursos de água com larguras inferiores a 10 metros situados em propriedades com área acima de 50 hectares.

As diferenças que resultam da aplicação do Código Estadual do Meio Ambiente catarinense em detrimento do Código Florestal brasileiro são significativas. Para ilustração numérica, tome-se uma microbacia hidrográfica rural ocupada por pequenas propriedades agrícolas com áreas até 50 hectares e com características fisiográficas que implicam em densidade de drenagem igual a 2 quilômetros de cursos de água para cada quilômetro quadrado de área, englobando as três classes de rios definidas pelo regime de vazão (efêmeros, intermitentes e perenes) e todos esses rios com largura inferior a 5 metros. Tais características físicas e de ocupação fundiária são típicas de Santa Catarina e podem ser encontradas em qualquer uma das regiões do Estado. Para essa microbacia prototípica, a aplicação do Código Florestal de 1965 implica em APPs de faixa ciliar equivalentes a $12 \%$ da área, desprezando-se a área ocupada pelos leitos dos cursos de água (uma faixa contínua de 2.000 metros vezes a largura da faixa ciliar de 60 metros resulta em 120.000 metros quadrados, ou 12 hectares a cada 100 hectares de área total). Na aplicação do Código Estadual do Meio Ambiente, mesmo que se ignore o fato de que nem todos os cursos de água são perenes, a APP de faixa ciliar se reduz para apenas um sexto da calculada pelo Código Florestal (ou 
apenas $2 \%$ da área de cada propriedade).

Os percentuais obtidos nessa rápida ilustração numérica sintetizam o forte apelo que a mudança do Código Florestal exerce sobre os agricultores e seus agentes políticos. Emblematicamente, uma reportagem de abrangência nacional, publicada logo após a entrada em vigor do Código Estadual do Meio Ambiente de Santa Catarina, apontava que "os agricultores consideram a medida um avanço, já os ambientalistas afirmam que é um retrocesso" (G1, 2009). Nessa reportagem, o chefe do executivo estadual catarinense considerava que a lei federal inviabiliza a permanência dos agricultores familiares no campo e defendia o direito de os Estados criarem seus próprios códigos ambientais. Nas palavras do governador: "Nós temos que escolher. Nós queremos lavouras ou favelas? Este código ambiental precisa ser flexibilizado para a realidade dos estados". O teor hiperbólico dessa declaração suscita muitas interpretações, mas a mais evidente é que a tomada de posição favorável a um dos lados de um debate ambiental tão acirrado revela o caráter polêmico do processo de encaminhamento da mudança na legislação em Santa Catarina.

\section{Proteção ambiental versus produção agrícola}

Pelas diversas razões discutidas neste texto, é plausível que a aplicação de regras ambientais, como as estabelecidas no Código Florestal brasileiro, possa inviabilizar economicamente alguns empreendimentos agrícolas. Também é verdadeiro, contudo, que, em questões ambientais, o interesse individual não pode se sobrepor ao interesse coletivo, seja da geração atual ou de futuras gerações beneficiárias de um ambiente saudável.

Ao longo da história de ocupação das terras catarinenses, concorreram para moldar o regime fundiário atual os fluxos migratórios engendrados pela colonização e os aspectos físicos do meio, principalmente o relevo acidentado. Em consequência, registram-se em Santa Catarina acentuados conflitos de uso nas Áreas de Preservação Permanente (APPs) situadas nos terrenos marginais aos cursos de água. Esses conflitos vêm se arrastando desde a publicação do Código Florestal, em 1965, mas se intensificaram à medida que aumentou a compreensão e a divulgação dos problemas ambientais associados às práticas agrícolas, como erosão hídrica do solo, lançamentos de dejetos aos corpos de água e uso indiscriminado de agrotóxicos.

A baixa conformidade da agricultura aos dispositivos do Código Florestal de 1965 , que ditam as normas para proteção das zonas ripárias, implica em danos sistemáticos a recursos compartilhados com outros setores da sociedade. Uma vez que o papel primordial das zonas ripárias, como corredores ecológicos e 
reserva da biodiversidade, enquadra-se na lista dos interesses difusos, com difícil valoração pelos agentes econômicos, os grupos contrários ao abrandamento da legislação apegam-se à proteção dos recursos hídricos como forma de amplificar a defesa das APPs. De fato, a proteção de mananciais apela a um bem escasso e com demanda crescente pela sociedade, principalmente pela população urbana encravada em regiões agrícolas, mas carrega o problema de ser uma visão utilitarista que se presta ao confronto com os argumentos que defendem a essencialidade e precedência da produção de alimentos com relação a quaisquer outras funções do meio.

No cenário atual do debate acerca das zonas ripárias, vislumbra-se uma clara tendência para abrandamento das exigências determinadas pelo Código Florestal de 1965, consideradas muito rígidas e incompatíveis com a realidade econômica e social dos agricultores. Em um extremo, o Código Estadual do Meio Ambiente de Santa Catarina limita a exigência de matas ciliares para os rios com regime perene de vazão e, no caso de propriedades rurais com área até 50 hectares e cursos de água perenes com largura inferior 5 metros, determina que devam ser respeitados apenas 5 metros de zona ripária ao longo de cada margem. São desconhecidas as razões para escolha dessa largura, mas ela chega ser anedótica quando se considera que mesmo árvores de pequeno porte podem apresentar envergaduras que ultrapassam os 5 metros.

Mudanças na legislação que implicam em redução drástica nas dimensões na zona ripária podem ter apelo eleitoral circunstancial para os políticos, pois de forma imediata parecem aumentar as possibilidades de renda dos agricultores. Além disso, inscrevem-se na tradição brasileira de negociar-se a norma mais do que exigir-se seu cumprimento. No entanto, são tão evidentes as funções ambientais exercidas pelas zonas ripárias, que preservá-las deveria ser tarefa dos agentes públicos, não o contrário. Compatibilizar a necessidade de produção agrícola, a geração de renda no campo e a proteção ambiental é o desafio real a ser ponderado pela sociedade. Nesse desafio não cabe a costumeira simplificação de se abrandar as normas como forma de encobrir a ausência de efetividade do poder público em fazer com que se cumpra a lei.

Considerações finais: proteção ambiental com produção agrícola

É natural que se espere do meio rural provisão de alimentos, fibras e cultivos para fins energéticos. Menos usual é reconhecer a propriedade rural como detentora de outras funções que podem rivalizar em importância com a produção agrícola praticada sob diferentes modalidades. O senso comum de entender a zona rural como lugar de cultivadores da terra e pastores e a zona urbana como lugar de artesãos, operários, comerciantes e profissionais liberais 
advém de uma delimitação territorial arbitrária que ignora as interfaces, as transições suaves e as transposições entre os agrupamentos do campo e da cidade. Não haveria problemas práticos se tal delimitação arbitrária fosse meramente uma formalidade cadastral, porém Veiga (2003) discute, em um de seus ensaios, as implicações da polarização rural-urbano para as políticas de desenvolvimento no Brasil, em especial sobre as inadequadas políticas setoriais que alijam parte da população que vive em cidades minúsculas de benefícios dirigidos aos moradores do meio rural, e vice-versa.

Mais do que populações estanques, o fluxo entre atividades urbanas e rurais determina fronteiras cada vez mais difusas entre a cidade e o campo. Em adição, não se pode incorrer "no vício de se resumir o rural ao agrário", como expôs Veiga (2004, p. 64), em sua crítica à hipótese de completa urbanização, lançada pelo filósofo e sociólogo Henri Lefebvre, em 1970. Portanto, em quaisquer considerações acerca do papel social da agricultura não se deve incidir na simplificação de vinculá-la unicamente à obtenção de bens agrícolas e aos conflitos ambientais que decorrem da utilização das terras. Esse afrouxamento da relação entre o rural e o agrário é ainda mais notável na agricultura familiar, na qual as rendas advindas de atividades não agrícolas podem constituir-se em alternativas para manter moradores no campo, principalmente os jovens.

Para abordar a questão de rendas não agrícolas no meio rural, emergiram, nas últimas décadas, os conceitos de pluriatividade do agricultor e multifuncionalidade da agricultura. Como revisado por Cazella e Roux (1999), "são considerados pluriativos todos os agricultores que, além das práticas agrícolas stricto sensu, executam a transformação e a venda direta da produção, o agroturismo, a proteção da natureza e a 'produção' de paisagens no interior da propriedade, assim como as atividades remuneradas que não estão intimamente ligadas à exploração agrícola". Por sua vez, dos trabalhos de Carneiro e Maluf (2005) e Bonnal e Maluf (2009) pode-se retirar que o conceito de multifuncionalidade remete à ideia de a agricultura atender demandas que fogem do compromisso tradicional de produção de bens para atender o mercado, modalidade esta também chamada sinteticamente de agricultura "produtivista". Uma importante distinção prática entre um e outro conceito é que a pluriatividade pode ampliar a renda dos agricultores por meio do exercício de trabalhos fora da agricultura e, ainda assim, reproduzir a produção convencional de bens agrícolas para o mercado, enquanto que multifuncionalidade implica utilizar outras dimensões existentes no espaço rural e transformá-las em oportunidade de renda e manutenção das famílias no campo. Em consequência, a adoção de uma agricultura multifuncional distancia-se da agricultura produtivista, em virtude da necessidade da exploração das chamadas "amenidades rurais", geralmente não compatíveis com uso intensivo do solo, criações concentradas e emprego maciço 
de insumos agrícolas.

Em outras palavras, enquanto na agricultura produtivista o objetivo é principalmente o produto, na agricultura multifuncional o enfoque central é a qualidade do processo de produção, que engloba tanto as características finais do bem agrícola, como as relações ambientais e laborais intrínsecas na atividade produtiva. Portanto, é no contexto de agricultura multifuncional que a aproximação da proteção ambiental com a produção agrícola pode se tornar possível.

Quando aplicado aos recursos hídricos, o conceito de multifuncionalidade da agricultura pode repercutir positivamente na sociedade, não tanto pelo caráter mais abrangente ensejado pela proteção ambiental, mas pelo interesse mais pragmático de se dispor de água com qualidade para abastecimento público. Nesse aspecto, reforçam-se e confundem-se as estratégias de ação voltadas à segurança alimentar e à segurança hídrica. Considerando-se, portanto, serem indissociáveis a qualidade do modo de produzir na agricultura e o acesso à água com qualidade pela população, torna-se evidente que a pressão atual pelo abrandamento da legislação referente à proteção das áreas ripárias é inoportuna. Desafortunadamente, pelo desenrolar dos acontecimentos sobre as áreas ripárias no cenário político atual, também fica evidenciado que não estão sendo bem sucedidos os esforços de convencimento da sociedade sobre as vantagens de proteger os recursos hídricos por intermédio da promoção de práticas agrícolas ambientalmente mais adequadas.

Abstract: This paper presents and discusses the issue about the protection of riparian zones in agricultural areas of southern Brazil, especially in the state of Santa Catarina, where family farming prevails practiced in small properties. The legal requirements set by the Brazilian Forest Code of 1965 are presented before the limitations to comply with the law imposed by cultural factors, physical environment and size of the agricultural properties. In order to illustrate the problem, the two prevailing streams in the debate are compared regarding the use of riparian areas in Santa Catarina: the application of existing legal provisions versus law flexibility to meet current uses in permanent preservation areas. Keywords: Riparian Zones, Riparian Forest, Water Resources, Family Agriculture, Forests.

\section{Referências Bibliográficas}

AB'SABER, AZIZ N. "O suporte geoecológico das florestas beiradeiras (ciliares)". In: R. R. Rodrigues, H. de F. Leitão Filho (eds.) Matas ciliares: conservação e recuperação. 2a ed. São Paulo: Editora USP: Fapesp, 2001, p. 15-26. 
BONNAL, P.; MALUF, R. S. "Políticas de desenvolvimento territorial e multifuncionalidade da agricultura familiar no Brasil". Política \& Sociedade, n. 14, 2009, p. 211-250.

BRASIL. LEI № 4.771, DE 15 DE SETEMBRO DE 1965. Institui o novo Código Florestal. Publicado no D.O.U. de 16.9.1965

BRASIL. LEI № 9.605, DE 12 DE FEVEREIRO DE 1998. Dispõe sobre as sanções penais e administrativas derivadas de condutas e atividades lesivas ao meio ambiente, e dá outras providências. Publicado no D.O.U. de 13.2.1998.

CAPOBIANCO, J. P. R. Dossiê Mata Atlântica 2001. Rede de ONGs da Mata Atlântica-Instituto Socioambiental-Sociedade Nordestina de Ecologia. Projeto Monitoramento Participativo da Mata Atlântica, 2001. Documento eletrônico disponível em http://www.socioambiental.org/inst/pub/detalhe_down_html?codigo=54. Acesso em 19/07/2010.

CEPA - Centro de Socioeconomia e Planejamento Agrícola. Números da Agropecuária Catarinense março/2008. Florianópolis: EPAGRI/CEPA, 2008 Documento eletrônico disponível em http://cepa.epagri.sc.gov.br/. Acesso em 19/07/2010.

CAZELLA, A. A.; ROUX, B. "Agribusiness em questão: a emergência da agricultura multifuncional". Estudos Sociedade e Agricultura 13, 1999, p. 46-69.

CARNEIRO, M. J.; MALUF, R. S. "Multifuncionalidade da agricultura familiar". In: B. Filho (Organizador). Agricultura familiar e desenvolvimento territorial: contribuições ao debate. Brasília: Universidade de Brasília, Centro de Estudos Avançados Multidisciplinares, Núcleo de Estudos Avançados. v. 5 n. 17, 2005, p. 43- 58.

DEAN, W. A ferro e fogo: a história da devastação da Mata Atlântica brasileira. São Paulo: Companhia das Letras, 1996.

DENARDI, Reni A. "Agricultura familiar e políticas públicas: alguns dilemas e desafios para o desenvolvimento rural sustentável". Agroecol. e Desenv. Rur. Sustent., v.2, n.3, jul/set, 2001.

EMBRAPA. Diagnóstico das propriedades suinícolas da área de abrangência do Consórcio Lambari, SC. Concórdia (SC): CNPSA, 2003.

G1- Portal de notícias da Globo. Novo Código Ambiental de Santa Catarina entra em vigor em meio a polêmica. Documento eletrônico publicado em 16/04/09 e disponível em http://g1.globo.com/Noticias/Brasil/0,,MUL1088313-5598,00. html. Acesso em 15/07/2010. 
GLEICK, Peter H. (Org.) The world's water 2008-2009: the biennial report on freshwater resources. Washington: Islandpress, 2009. Alguns dados disponíveis em http://www.worldwater.org. Acesso em 19/07/2010.

PELUSO, V. A. Jr. Aspectos geográficos de Santa Catarina. Florianópolis: Ed. da UFSC, 1991.

RODRIGUES, R. R. "Florestas ciliares? Uma discussão nomenclatural das formações ciliares". In: R. R. Rodrigues, H. de F. Leitão Filho (Eds.). Matas ciliares: conservação e recuperação. 2ª ed. São Paulo: Editora USP: Fapesp, 2001, p. 91-99.

SANTA CATARINA. LEI N¹4.675, DE 13 DE ABRIL DE 2009. Institui o Código Estadual do Meio Ambiente e estabelece outras providências.

TRENTINI, E. C. Agricultura "criminosa": atividades agrícolas avaliadas à luz do Código Florestal de 1965. Florianópolis, 124f. Dissertação (Mestrado em Agroecossistemas), Centro de Ciências Agrárias, Universidade Federal de Santa Catarina, 2004.

VEIGA, José Eli da. "Cidades Imaginárias". In: J. E. da Veiga. Cidades Imaginárias: O Brasil é menos urbano do que se calcula. 2. ed. Campinas, SP: Autores Associados, 2003, p. 55-58.

Destinos da ruralidade no processo de globalização. Estudos Avançados 18(51), 2004, p. 51-67.

WANDERLEY, MARIA de N. B. "Raízes históricas do campesinato brasileiro". XX Encontro Anual da ANPCS GT 17, Processos Sociais Agrários, Caxambu, MG. Outubro, 1996. 